\title{
Deformation mechanisms and effect of oxygen addition on mechanical properties of Ti-7.5Mo alloy with $\alpha$ " martensite
}

\author{
Xin Ji*, Ivan Gutierrez-Urrutia, Satoshi Emura, and Koichi Tsuchiya
}

National Institute for Materials Science, Tsukuba, Japan

"JI.Xin@nims.go.jp

\section{$\underline{\text { Abstract }}$}

Effect of oxygen content as an important interstitial solute on the microstructure and mechanical properties of Ti-7.5Mo alloy was investigated. With increasing the oxygen content, the yielding strength, ultimate tensile strength and Young's modulus of Ti-7.5Mo-xO ( $x=0,0.2,0.3,0.4,0.5)$ alloys increased, while the elongation showing a decreasing tendency. Solid-solution strengthening by the oxygen atoms has been addressed as the main strengthening mechanism. Ti-7.5Mo-xO ( $\mathrm{x} \leq 0.3)$ alloys have been regarded with an excellent combination of high yield strength $(\sim 640 \mathrm{MPa})$ and elongation ( $28 \%$ ), as well as low Young's modulus ( $\sim 60 \mathrm{GPa})$. The deformation microstructure of orthorhombic- $\alpha$ " martensite in Ti-7.5Mo alloy was also investigated by tracking a change in the microstructure of a selected area upon tensile deformation. Deformation twins induced by $5 \%$ tensile straining was identified as $\{112\}_{\alpha^{n}}{ }^{-t y p e ~ I ~ t w i n s, ~ w h i c h ~ h a d ~ n o t ~ b e e n ~ r e p o r t e d ~}$ before in $\alpha$ "martensite in $\beta$-Ti alloys.

Keywords: $\beta$-Titanium alloys, biomaterials, orthorhombic- $\alpha$ " martensite, oxygen, deformation twinning

\section{Introduction}

Recently, novel $\beta$-Ti alloys have been developed for biomedical applications with lower modulus, better formability and non-toxic elements (i.e.Al- and V-free), such as Ti-7.5Mo (wt.\%) [1], Ti-15Mo (wt.\%) [2], and Ti-29Nb-13Ta-4.6Zr (wt.\%, TNTZ) [3] alloys. In particular, due to the low Young's modulus ( $65 \mathrm{GPa}$ ) [4] and good bone-implant interaction [5], the binary Ti-7.5Mo alloy with an orthorhombic- $\alpha$ " crystal structure has been described as a promising candidate for implant material. The orthorhombic- $\alpha$ " phase in Ti-7.5Mo alloy is obtained by means of martensitic transformation from bcc- $\beta$ phase upon fast cooling. However, the relatively low strength in the solution-treated state of this alloy is still a major drawback. Excellent mechanical properties, combining high strength and low Young's modulus, are required for the design of biomaterials.

It is well established that the mechanical properties of titanium alloys are sensitive to the interstitial solutes such as oxygen, nitrogen, carbon and hydrogen [6,7]. Extensive efforts have revealed oxygen as an effective element to improve the strength of titanium alloys due to its solid-solution strengthening effect [6]. The purpose of the present study is to investigate the effect of oxygen content on the microstructure and mechanical properties of Ti-7.5Mo alloy. A better understanding of deformation mechanisms of $\alpha^{\prime \prime}$ martensite is also essential for the development of highperformance $\beta$-Ti alloys. So far, few studies have analyzed deformation behaviors of $\alpha^{\prime \prime}$ martensite in $\beta$-Ti alloys, especially in Ti-Mo systems [8-10]. These studies have reported $\{130\}_{\alpha^{\prime \prime}}$-compound twinning in a Ti-25Ta-20Nb (wt.\%) alloy [8], and $\{130\}_{\alpha^{\prime \prime}}{ }^{-c o m p o u n d}$ and $\{103\}_{{ }^{\prime \prime}}{ }^{-c o m p o u n d}$ twinning in a Ti-42Nb (wt.\%) alloy [9]. Therefore, the aim of this study is also to investigate the deformation behaviors of $\alpha^{\prime \prime}$ martensite in Ti-7.5Mo alloy.

\section{$\underline{\text { 2. Material and experiments }}$}

The ingot of Ti-7.5Mo-xO $(\mathrm{x}=0,0.2,0.3,0.4,0.5$ (wt.\%), nominal composition) alloys were prepared by cold crucible levitation melting. The amount of oxygen was controlled by the addtion of $\mathrm{TiO}_{2}$. These alloys thereafter are named as $00,0.20,0.30,0.40$ and 0.50 . The ingots were hot-forged as $1273 \mathrm{~K}$ and then hot-rolled at $1173 \mathrm{~K}$ into plates of $290 \mathrm{~mm}($ length) $\times 50 \mathrm{~mm}$ (wide) $\times 10$ $\mathrm{mm}$ (thickness) followed by air-cooling. The solution-treatment was performed at $1173 \mathrm{~K}$ for 1 hour followed by water quenching.

(C) The Authors, published by EDP Sciences. This is an open access article distributed under the terms of the Creative Commons Attribution License 4.0 (http://creativecommons.org/licenses/by/4.0/). 
Tensile tests were conducted in an INSTRON 5581 testing machine with an initial strain rate of $2.8 \times 10^{-4} \mathrm{~s}^{-1}$. Microstructure characterizations were performed by a Zeiss Sigma field-emission scanning electron microscope (SEM) equipped with a backscattered electron (BSE) detector. Transmission electron microscope (TEM) observations were carried out on a JEOL JEM-2100F microscope. TEM thin foils were prepared by using a dual-beam focused ion beam (FIB) on a Zeiss Auriga instrument. X-ray diffraction (XRD) analysis was carried out on a Rigaku TTR III diffractometer with $\mathrm{Cu}-\mathrm{K}_{\alpha}$ radiation operated at $40 \mathrm{kV}-150 \mathrm{~mA}$

\section{Results and discussion}

3.1 Phase constitution

Fig. 1 shows XRD results of the prepared Ti-7.5Mo-xO $(\mathrm{x}=0,0.2,0.3,0.4$ and 0.5$)$ alloys after water quenching. An orthorhombic- $\alpha$ " martensite is shown as the main phase in these samples. This implies that the phase transformation $\beta \rightarrow \alpha^{\prime \prime}$ is almost complete upon water quenching. It is worth noticing that the additional $(110)_{\beta}$ reflection at $2 \theta=38.7^{\circ}$, as well as the $(200)_{\beta}$ reflection at $2 \theta=55.8^{\circ}$ with higher intensity can be identified in $0.5 \mathrm{O}$ alloy. The $\beta \rightarrow \alpha$." martensitic transformation may be suppressed by the high oxygen addition $(\sim 0.5$ wt.\%), which agrees with the previous reports [11,12]. It has been proposed by Ghosh and Olson $[13,14]$ that the interstitial elements (such as oxygen) may induce large local strain fields, acting as obstacles to the dislocation motion and thus leading to the enhanced frictional work against the motion of martensite interface. An additional $\alpha$ reflection at $2 \theta=62.8^{\circ} \mathrm{can}$ also be identified in the quenched $0.4 \mathrm{O}$ sample, Fig. 1. The number and intensity of $\alpha$ peaks increased with the oxygen content to $0.5 \mathrm{wt} \%$, which indicates that more aphase exists in the quenched $0.5 \mathrm{O}$ sample. The interstitial oxygen atoms are suggested to stabilize the $\alpha$ phase, and thus increase the $\beta$ transus temperature of Ti-7.5Mo alloy [15]

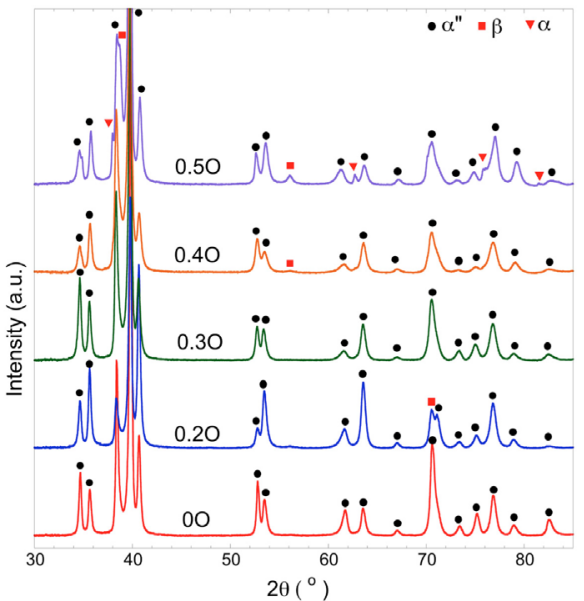

Fig. 1 X-ray diffraction (XRD) profiles of the as-quenched Ti-7.5Mo-xO $(x=0,0.2,0.3,0.4$ and $0.5(w t . \%))$ alloys.

3.2 As-quenched microstructure

Fig. 2 shows BSE images of the as-quenched Ti-7.5Mo alloys with different contents of oxygen. Fine and acicular $\alpha^{\prime \prime}$ martensite plates are shown distributing homogeneously over the whole $\beta$ matrix grains. From the insets with higher magnification images, it can be clearly seen that the $\alpha^{\prime \prime}$ martensite plates with an average thickness of $\sim 1 \mu \mathrm{m}$ containing internal twining structures [15]. The inset of Fig. 2(d) displays the precipitated $\alpha$ plates both along the grain boundaries and in the grain interiors of $0.4 \mathrm{O}$ alloy. Fig. 2(d) of $0.5 \mathrm{O}$ alloy indicates more $\alpha$ plates distributing in the grain interiors and along the grain boundaries. The increasing area fraction of $\alpha$ phase with increasing oxygen content also agrees with the XRD result (Fig.1). 


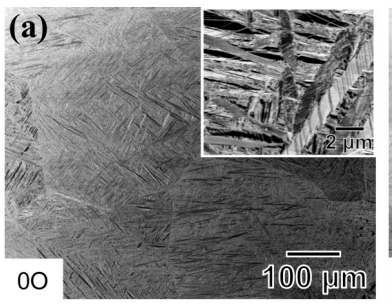

(d)

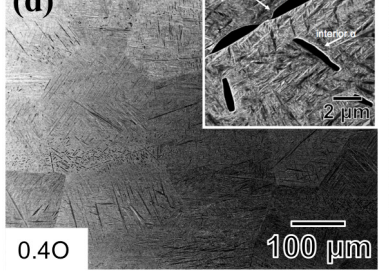

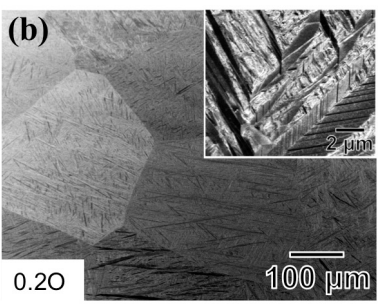

(e)

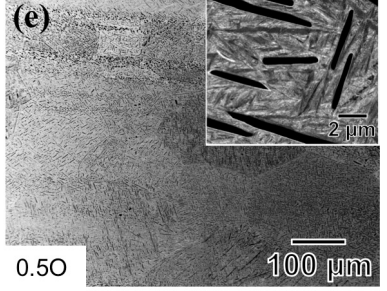

Fig. 2 Low-magnification and high-magnification backscattered electron (BSE) images of theas-quenched microstructures taken from Ti-7.5Mo alloyswith different levels of oxygen: (a) 00 , (b) 0.20 , (c) 0.30 , (d) $0.4 \mathrm{O}$ and (e) 0.50 .

3.3 Tensile properties

The engineering stress $\left(\sigma_{\mathrm{e}}\right)$-strain $\left(\varepsilon_{\mathrm{e}}\right)$ curves of the as-quenched Ti-7.5Mo-xO $(\mathrm{x}=0,0.2,0.3,0.4$ and $0.5(\mathrm{wt} . \%))$ alloys are shown in Fig. $3(\mathrm{a})$. The sudden fracture can be observed in 0.40 and 0.50 alloys. Tensile properties are summarized in Figs. 3(b) and (c). There is an obvious increase of $0.2 \%$ offset yield strength (YS) from 386 MPa to 826 MPa with increasing the oxygen content from 0 to $0.5 \mathrm{wt} . \%$. The ultimate tensile strength (UTS) also exhibits an increasing tendency, whereas the total elongation (tEL) decreases with the oxygen content increases. Young's modulus (E) increases from $55.4 \mathrm{GPa}$ of 00 alloy to $73.9 \mathrm{GPa}$ of 0.50 with increasing the oxygen content.

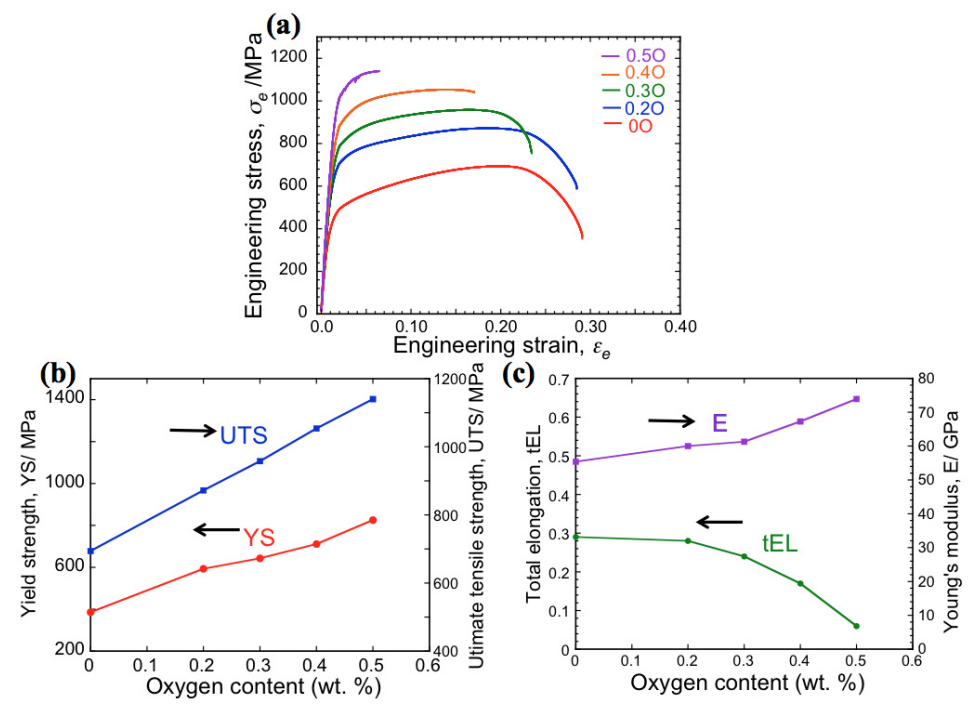


Fig. 3 (a) Engineering stress-strain curves, tensile properties for (b) $0.2 \%$ offset yield strength (YS) and ultimate tensile strength (UTS), and (c) total elongation (tEL) and Young's modulus (E) with different oxygen content of the as-quenched Ti-7.5Mo-xO $(x=0,0.2,0.3,0.4$ and $0.5(w t . \%))$ alloys.

The results of tensile properties in Fig. 3 reveal that the addition of oxygen atoms is very effective to increase the strength. This can be ascribed to the effect of solid-solution strengthening with the addition of interstitial oxygen atoms [6]. Fig. 4 [15] shows the relationship between the yield strength and Young's modulus (Fig. 4(a)), and that between total elongation and Young's modulus (Fig. 4(b) of the Ti-7.5Mo-xO ( $\mathrm{x}=0,0.2,0.3,0.4$ and 0.5$)$ alloys in this work. The mechanical properties of several biomedical titanium alloys are also displayed for comparison. It can be observed that 0.20 and 0.30 alloys with low Young's modulus ( $<65 \mathrm{GPa}$ ) exhibit an excellent combination of high yield strength and large elongation. While most of other alloys are multicomponent systems, the present alloy is based on simply binary alloys. This may be advantageous in terms of the materials cost and processing point of view. Therefore, Ti-7.5Mo alloy with oxygen addition $\leq 0.3$ wt. $\%$ is considered to have good potential as biomedical materials [15]
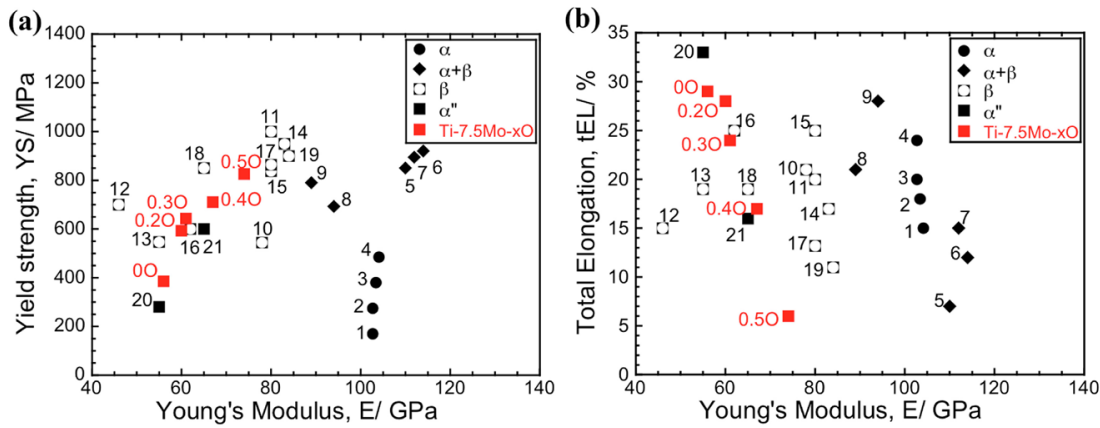

Fig. 4 Plots of (a) yield strength vs. Young's modulus, and (b) total elongation vs. Young's modulus of Ti-7.5Mo-x0 ( $x=0,0.2,0.3,0.4$ and 0.5$)$, as well as several biomedical titanium alloys. $\alpha$-type: \#1-4 c.p. Ti grade 1-4; $\alpha+\beta$-type: \#5 Ti-6Al-4V (annealed), \#6 Ti-6Al-7Nb (wrought), \#7 Ti-5Al-2.5Fe (cast); $\beta$-type: \#8 Ti-15Sn-4Nb-2Ta-0.2Pd (annealed) and \# 9 Ti-15Zr-4Nb-2Ta-0.2Pd (annealed), \#10 Ti-15Mo (annealed), \#11 Ti-12Mo-6Zr-2Fe (annealed), \#12 Ti-24Nb-4Zr-7.9Sn (hot-rolled), \#13 Ti-35Nb-7Zr-5Ta (annealed), \#14 Ti-15Mo-2.8Nb-0.2Si (annealed) and \#15 Ti-15Mo-5Zr-3Al (solution-treated), \#16 Ti-29Nb-13Ta-4.6Zr (solution-treated), \#17 Ti-29Nb-13Ta-4.6Zr (aged), \#18 Ti-23Nb-0.7Ta-2Zr-1.20 (solution-treated), \#19 Ti-13Zr-13Nb (aged); $\alpha$ "-type: \#20 Ti-23Nb-0.7Ta-2Zr (solution-treated), and \#21 Ti-29Nb-13Ta-4.6Cr (cold-rolled) [15].

3.4 Deformation mechanism of $\alpha$ " martensite

Evolution of microstructures of a selected area of $\alpha$ " martensite sample was tracked upon tensile deformation and the results are shown in Fig. 5 . The microstructure of as-quenched state is displayed in Fig. 5(a). Several $\alpha$ " martensite plates can be observed and some of them contain transformation twinning structures [15,16]. Upon 5\% tensile straining, new deformation bands were induced in the martensite plates, as indicated by the red arrows in Fig. 5(b). High magnification images are shown in Figs. 5(c) and (d), which are taken from the framed regions in Figs. 5(a) and (b), respectively. Two variants of deformation bands are observed to nucleate at onea" plate boundary and then propagate to the other side of the boundary, Fig. 5(d). 

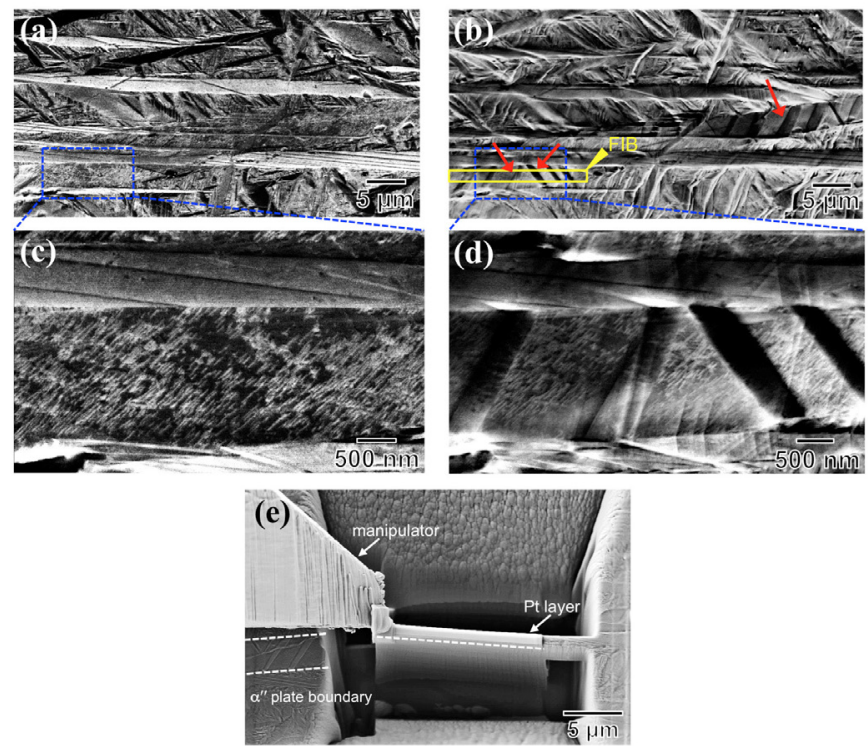

Fig. 5 Sequential BSE images showing the microstructures of the as-quenched state, (a), and after 5\% straining, (b). Higher magnification images of (c) and (d) are taken from the boxed regions in (a) and (b), respectively. (e) Secondary electron image of in-depth TEM lamella cut from the deformation bands.

The deformation bands were further characterized by TEM on a FIB lift-out sample prepared in the cross-section perpendicular to the sample surface, Fig. 5(e). The TEM image of the deformation bands is shown in Fig. 6(a). Selected area electron diffraction (SAED) patterns taken from the matrix (Fig. 6(b)), twin (Fig. 6(c)) and matrix/twin interface (Fig. 6(d)) reveal a twin relationship between the deformation band and crystal matrix. In particular, the twin plane was identified as (112) $)_{\alpha^{\prime \prime}} \mathrm{M/T}$, corresponding to $\{112\}_{\alpha^{\prime \prime}}$-type I deformation twins [17]. To the authors' knowledge, $\{112\}_{\alpha^{\prime \prime}}$-type I deformation twinning has never been reported as active twinning modes in $\alpha^{\prime \prime}$ martensite in $\beta$-Ti alloys. Based on Bilby-Crocker theory [18], deformation twinning is described by four crystallographic elements, namely, $K_{1}, K_{2}, \eta_{1}$ and $\eta_{2}$, where $K_{1}$ is the twin plane, $\eta_{1}$ is the twin direction, $K_{2}$ is the reciprocal or conjugate twin plane, and $\eta_{2}$ is the reciprocal or conjugate twin direction. In the present case, $K_{1}=$ $\{112\}$ was experimentally confirmed, Fig. 6 . The other twin elements $\left(K_{2}, \eta_{1}\right.$, and $\left.\eta_{2}\right)$ of the $\{112\}_{\alpha^{\prime \prime}}$ type I twinning were calculated with the lattice parameters of $\alpha^{\prime \prime}$ martensite in the Ti-7.5Mo alloy, i.e., $a_{\alpha^{\prime \prime}}=0.3002 \mathrm{~nm}, b_{\alpha^{\prime \prime}}=0.5033 \mathrm{~nm}$, and $c_{\alpha^{\prime \prime}}=0.4680 \mathrm{~nm}[16]$. Then, the crystallographic elements are $K_{1}=\{112\}, \eta_{1}=<-6.463,-1,3.732>, K_{2}=\{-2.586,-1,4.379\}$, and $\eta_{2}=<312>$. It is noted that the $K_{2}$ and $\eta_{1}$ elements have irrational Miller indices for $\{112\}_{\alpha^{\prime \prime}}$ type I twinning. The shear magnitude $s$ is given by $s=2 \cot (2 \phi)$, where $(2 \phi)$ is the angle between $K_{1}$ and $K_{2}$ planes, and we obtained $s=0.199$. In $\beta$-Ti alloys, several studies have reported the activation of different twinning modes with $s \sim 0.2-0.3[8-10]$, which is close to the shear magnitude of the $\{112\}_{\alpha^{\prime \prime}}$-type I twinning mode ( $\left.s=0.199\right)$.
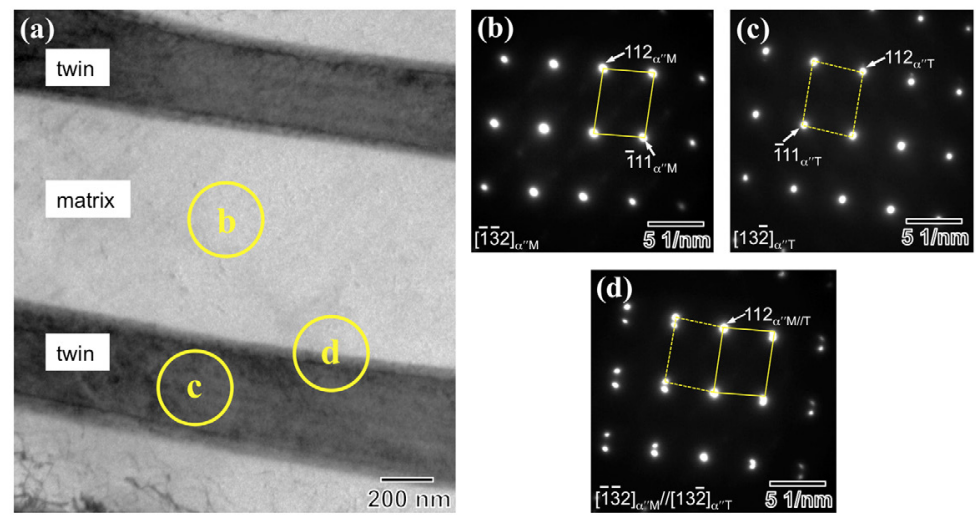

Fig. 6 (a) TEM image of the lamella prepared by FIB, as indicated in Fig. 5(e). (b)-(d) SAED patterns taken from the circled regions indicated in (a). 


\section{Conclusion}

The effect of oxygen contents on the microstructures and mechanical properties of as-quenched Ti-7.5Mo (wt.\%) alloy and the deformation mechanism of $\alpha$ "martensite in Ti-7.5Mo alloy have been investigated. The Ti-7.5Mo-xO $(x=0,0.2,0.3,0.4$ and 0.5$)$ alloys consist mainly of orthorhombic- $\alpha$ " martensite. Additional $\alpha$ phase has been identified in 0.40 and 0.50 alloys, due to the $\alpha$ stabilizing effect by oxygen atoms. The increasing oxygen contents of Ti-7.5Mo alloy result in the increase of yield strength, ultimate tensile strength, and Young's modulus, whereas the decrease of total elongation. This is ascribed to the solid-solution strengthening effect by the addition of oxygen atoms. The $\alpha^{\prime \prime}$ martensite in Ti-7.5Mo alloy undergoes a $\{112\}_{\alpha^{\prime \prime}}$-type I deformation twinning mode upon tensile deformation, which has been identified for the first time in $\beta$-Ti alloys.

\section{$\underline{\text { 5. References }}$}

[1] W.F. Ho, C.P. Ju, J.H. Chern Lin, Biomaterials 20 (1999) 2115-2122.

[2] L. Zardiackas, D. Mitchell, J. Disegi, in: Med. Appl. Titan. Its Alloy. Mater. Biol. Issues, ASTM International, 100 Barr Harbor Drive, PO Box C700, West Conshohocken, PA 19428-2959, 1996, 60-75. [3] D. Kuroda, M. Niinomi, M. Morinaga, Y. Kato, T. Yashiro, Mater. Sci. Eng. A 243 (1998) 244-249.

[4] C.C. Chung, S.W. Wang, Y.C. Chen, C.P. Ju, J.H. Chern Lin, Mater. Sci. Eng. A 631 (2015) 52-66.

[5] D.J. Lin, C.C. Chuang, J.H. Chern Lin, J.W. Lee, C.P. Ju, H.S. Yin, Biomaterials 28 (2007) 2582-2589.

[6] H. Conrad, Prog. Mater. Sci. 26 (1981) 123-403.

[7] M. Besse, P. Castany, T. Gloriant, Acta Mater. 59 (2011) 5982-5988.

[8] E. Bertrand, P. Castany, Y. Yang, E. Menou, T. Gloriant, Acta Mater. 105 (2016) 94-103.

[9] M. Tahara, N. Okano, T. Inamura, H. Hosoda, Sci. Rep. 7 (2017) 1-11.

[10] P. Castany, Y. Yang, E. Bertrand, T. Gloriant, Phys. Rev. Lett. 117 (2016) 1-6.

[11] J. I. Kim, H.Y. Kim, H. Hosoda, S. Miyazaki, Mater. Trans. 46 (2005) 852-857.

[12] M. Tahara, H.Y. Kim, T. Inamura, H. Hosoda, S. Miyazaki, Acta Mater. 59 (2011) 6208-6218.

[13] G. Ghosh, G.B. Olson, Acta Metall. Mater. 42 (1994) 3361-3370.

[14] J.Y. Yan, G.B. Olson, J. Alloys Compd. 673 (2016) 441-454.

[15] X. Ji, S. Emura, T. Liu, K. Suzuta, X. Min, K. Tsuchiya, J. Alloys Compd. 737 (2018) 221-229.

[16] X. Ji, I. Gutierrez-urrutia, S. Emura, T. Liu, T. Hara, X. Min, K. Tsuchiya, Sci. Technol. Adv. Mater. 20 (2019) 401-411.

[17] A.G. Crocker, J. Nucl. Mater. 16 (1965) 306-326

[18] B.A. Bilby, A.G. Crocker, Proc. R. Soc. A 288 (1965) 240-255. 